\title{
ПРОГНОЗ УСТОЙЧИВОСТИ СКЛОНОВ УЧАСТКА БЕРЕГА ХИМКИНСКОГО ВОДОХРАНИЛИЩА
}

\author{
Ушаков Александр Сергеевич 1 , \\ ushakovi@inbox.ru \\ Кулешов Александр Петрович1, \\ 87kuleshov@mail.ru \\ 1 Российский государственный геологоразведочный университет им. Серго Орджоникидзе, \\ Россия, 117997, г. Москва, ул. Миклухо-Маклая, 23.
}

\begin{abstract}
Актуальность работы обусловлена необходимостью анализа существующих способов расчета коэфффициента устойчивости склона. В работе проанализированы три метода расчета, приведен анализ по рациональной области использования каждого метода. Рекомендации по выбору методов расчета разработаны на основе анализа существующих способов расчета, сравнения их применительно к практическим вычислениям.

Цель: прогнозный расчет устойчивости склона участка берега Химкинского водохранилища, сравнительный анализ величин коэфффициентов устойчивости, полученных различными методами с использованием современного математического аппарата, реализованного в программных комплексах: «PSK-98M5», «SCAD Office» и «Plaxis», оценка возможности применения используемых численных способов расчета.

Методы: анализ отечественного и зарубежного опыта расчета устойчивости склонов, сбор и оценка имеющейся инженерно-геологической информации, выбор граничных условий, математическое моделирование, сопоставление результатов расчетов, полученных различными методами, оценка уязвимости объектов и прогноз развития деформаций в основании зданий вследствие оползневого процесса.

Результаты. Математические расчеты проведены с помощью различных программных комплексов с использованием нескольких моделей и методов в соответствии с рекомендациями действующей нормативной документации. Из результатов расчетов следует, что более высокий коэфффициент устойчивости получен при расположении нагрузки от проектируемого сооружения выше по склону, и наоборот, при расположении ниже по склону той же нагрузки коэффрициент устойчивости уменьшается. Программный комплекс «SCAD Office» дает завышенные результаты. Это связано, по всей видимости, с тем, что в данной программе геометрические параметры склона фрактически никак не вводятся. Наиболее приближенными к действительности являются результаты, полученные в программе «Рlaxis», так как она разбивает введенную модель на огромное количество простых геометрических фигур (треугольников) и значения коэфффициента считаются в каждой узловой точке. Это обстоятельство существенно увеличивает точность расчета и намного приближает математическую модель к природным условиям.
\end{abstract}

\section{Ключевые слова:}

Прогноз устойчивости, коэфрфициент запаса, граничные условия, деформации и напряжения, линия скольжения, расчетное сечение, физико-механические характеристики,

метод конечных элементов, программный комплекс, склон, сравнительный анализ.

\section{Введение}

При большом разнообразии инженерно-геологических условий территории г. Москвы нередко, при строительстве новых сооружений на неустойчивых грунтах, приходиться прибегать к расчетам устойчивости склонов [1, 2 и др.].

Неучёт таких моментов, как оползневые склоны, суффозионный вынос, т. е. процессов, приводящих к сползанию или разрушению склона, может привести к деформациям, разрушениям сооружений, а также нанести вред здоровью человека и привести к летальному исходу.

Поэтому при осуществлении застройки на таких участках необходим точный расчет коэффициента запаса устойчивости склона, который позволит надежно эксплуатировать проектируемые здания и сооружения.

Определение формы и пространственного положения критической поверхности скольжения с минимальным коэффициентом запаса является одним из ключевых вопросов анализа устойчивости склонов [3, 4].
Коэффициент запаса устойчивости определяет соотношение между сдвигающими напряжениями на поверхностях скольжения и сопротивлением грунта сдвигу. Его величину рекомендуется принимать в зависимости от класса сооружений.

В соответствии с указаниями пП. 4.2.11, 4.4.11 СП 11-105-97 часть 2 и П. 6.7.2.9 СП 47.13330.2016 для обеспечения надежности оценок и прогнозов устойчивости склонов рекомендуется осуществлять расчеты различными методами в целях повышения надежности полученных результатов $[5,6]$.

Для каждого типа склонов рекомендуется задавать не менее одного расчетного створа по направлению ожидаемого оползневого смещения с захватом по высоте всей потенциально неустойчивой зоны [7, 8 и др.].

Способы и методы выполнения расчетов устойчивости склонов рекомендуется принимать согласно имеющимся методическим документам по количественной оценке и прогнозу устойчивости оползневых склонов [9, 10 и др.]. 
Целью данного исследования является сравнительный анализ методов расчета устойчивости склонов и прогнозный расчет склонов участка берега Химкинского водохранилища.

Для реализации поставленной цели решены задачи, связанные с рассмотрением инженерно-геологических условий северо-западной части г. Москвы и детальным изучением участка строительства:

- уточнение геоморфологических и геологических условий участка;

- выделение геологических тел до уровня МГТ-3 (ИГЭ);

- изучение гидрогеологических условий участка;

- выявление опасных экзогенно-геологических процессов (ЭГП) и определение области их развития;

- рассчет коэффициента устойчивости склона в программных комплексах «SCAD Office», «Plaxis» и PSK-98M5 [11].

Предметом исследования является локальная литотехническая система со своей областью влияния и сферой взаимодействия, в пределах которой рассмотрены следующие разделы: характеристика подсистемы «сооружение», методика и объемы выполненных инженерно-геологических изысканий, инженерногеологические условия территории строительства, рельеф и геоморфологические условия, стратиграфогенетические комплексы, гидрогеологические условия, физико-механические свойства грунтов, экзогенные геологические процессы, происходящие на рассматриваемой территории.

В работе были использованы технические отчеты и заключения, составленные МП «АПУ-Химки», а также фондовые материалы [12-14 и др.].

\section{Инженерно-геологическая характеристика участка}

Исследуемый объект расположен на левом берегу Химкинского водохранилища, на участке, предназначенном для строительства многоэтажной жилой застройки с культурно-оздоровительным центром по адресу: Московская область, городской округ Химки, микрорайон Левобережный, ул. Библиотечная.

Проектируемая застройка включает в себя:

1) три индивидуальных 17-ти этажных секционных жилых дома и встроено-пристроенный оздоровительный центр к жилому дому. Здания сложной формы в плане, габариты $35 \times 35$ м, 1 этаж подземный, техподполье глубиной 2,5-3,0 м от поверхности земли. Предполагаемый тип фундамента монолитная ж/б плита на естественном основании. Нагрузка на фундамент 30-35 т/ $\mathrm{m}^{2}$;

2) дом детского творчества с кружковыми группами на 60 мест. Представляет собой индивидуальное трехэтажное здание социального назначения. Габариты $38 \times 27$ м, 3 этажа наземных и мансарда, 1 этаж подземный, техподполье глубиной 2,5-3,0 м от поверхности земли. Предполагаемый тип фундамента - монолитная ж/б плита на естественном основании. Нагрузка на фундамент 15-20 т/ $\mathrm{m}^{2}$;

3) проектируемая многоэтажная автопарковка имеет 6 наземных этажей и 1 подземный, габариты
$34 \times 68$ м, техподполье глубиной 2,5-3,0 м от поверхности земли. Предполагаемый тип фундамента - монолитная ж/б плита на естественном основании. Нагрузка на фундамент 550 т на опору.

В геоморфологическом отношении участок работ расположен в пределах пологонаклонной флювиогляциальной равнины, прорезанной руслом реки Химки, по долине которой сооружен канал имени Москвы. Абсолютные отметки поверхности площадки работ изменяются от 169,00 до 176,43 м. Поверхность участка представляет собой территорию с регулярными посадками деревьев, предназначенных для укрепления склона. В верхней части участка выполнена вертикальная планировка.

Геологический разрез площадки, по результатам ранее выполненных инженерно-геологических изысканий, изучен до глубины 40 м. По литологическому составу и физико-механическим свойствам грунтов в сфере взаимодействия выделено семь инженерногеологических элементов (ИГЭ):

- почвенно-растительный слой (pQIV) встречен повсеместно;

- современные техногенные (tQIV) накопления (ИГЭ-1) представлены насыпным грунтом с включениями обломков кирпича, мусора строительно-бытового;

- верхнечетвертичные покровные (prQIII) отложения (ИГЭ-2) представлены суглинком тугопластичным, с включениями остатков растений;

- средне-верхнечетвертичные водно-ледниковые отложения (fQII-III) представлены песком средней крупности, средней плотности, влажным до водонасыщенного, с пятнами ожелезнения, с редкими линзами суглинка мягкопластичного, с редкими прослоями песка мелкого, с включениями гравия и гальки (ИГЭ-3);

- $\quad$ среднечетвертичные ледниковые отложения (gQII) представлены суглинком полутвердым, с линзами песка мелкого, с прослоями суглинка тугопластичного, с включениями гравия, щебня и гальки, обводненным по прослоям песка мелкого (ИГЭ-4);

- среднечетвертичные водно-ледниковые (fQII) отложения распространены не повсеместно, представлены песком средней крупности, средней плотности, влажным до водонасыщенного, с частыми прослоями песка мелкого, местами до пылеватого (ИГЭ-5);

- нижнемеловые отложения $\left(\mathrm{K}_{1}\right)$ представлены песком мелким, до пылеватого, плотным, водонасыщенным (ИГЭ-6).

Гидрогеологические условия представлены двумя водоносными горизонтами.

Первый от поверхности водоносный горизонт приурочен к водно-ледниковым пескам средневерхнечетвертичного возраста (ИГЭ-3). Воды являются безнапорными.

Второй от поверхности водоносный горизонт приурочен к песчаным прослоям в ледниковых отложениях (ИГЭ-4), водно-ледниковым пескам среднечетвертичного возраста (ИГЭ-5) и нижнемеловым пес- 
кам (ИГЭ-6). Водоносный горизонт является субнапорным.

По типу подтопляемости территория относится к III-му типу с наиболее вероятной скоростью подъема уровня грунтовых вод 0,1-0,3 м/год в первые 10 лет периода эксплуатации. При величине критического уровня подтопления 3,0 м территория относится к неподтопляемой.

Из опасных экзогенных процессов, развитых на территории многоэтажной жилой застройки, следует отметить: сезонное промерзание грунтов, морозное пучение и снижение показателей прочностных и деформационных свойств грунтов вследствие их переувлажнения на локальных участках, аккумулирующих поверхностный сток.

В связи с присутствием значительного градиента в несвязных грунтах, чередованием относительно водоупорных и водоносных горизонтов, активной строительной и хозяйственной деятельности существует большая вероятность развития суффозионного и оползневого процессов.

Учитывая вышесказанное, можно предположить, что склон является потенциально оползневым, и поэтому необходимо провести ряд расчетов по оценке устойчивости склона и определению коэффициента устойчивости склона.

\section{Оценка устойчивости склона}

Для отдельных наиболее характерных участков склонов была выполнена серия расчетов устойчивости. Расчеты выполнялись тремя программными комплексами: «PSK-98M5», разработанным НПП «Сингеос»; «SCAD Office» и «Plaxis».

Программные комплексы «PSK-98M5» и «SCAD Office» базируются на одном из основных и популярных механико-математических методов при прогнозе устойчивости склона - методе круглоцилиндрической поверхности скольжения, рекомендуемом нормативными документами [15].

Этот метод весьма распространен в строительной практике и применяется с помощью самых различных приемов. Существует большое количество названий рассматриваемого метода и его разновидностей: методы Бишопа, Феллениуса и «Корпуса Инженеров № 1» и т. д. [16].

В программе «Рlaxis» реализуется метод конечных элементов (МКЭ) - наиболее эффективный современный способ численного решения инженерных, физических и математических задач инженерной геологии и механики грунтов, строительной механики.

Все расчеты выполнялись по линиям инженерногеологических разрезов 2-2а и 3-3a (рис. 1).

Первый профиль характеризует склон, ориентированный к водохранилищу, второй - участок склона в направлении от проектируемого здания в овраг.

Расчеты выполнялись при расчетных $(\alpha=0,95)$ значениях физико-механических характеристик грунтов. Прогнозируемые уровни грунтовых вод задавались незначительно (на 0,2-0,8 м) превышающими значения, зафиксированные при изысканиях. В расчетах была принята нагрузка на $1 \mathrm{~m}^{2}$ плиты 30-35 т/ $\mathrm{m}^{2}$ и пригрузка 1,3 кг/см² (0,13 МПа), равномерно распределенная по всей площади подошвы фундамента.
Соответственно, чтобы выполнить сравнительную оценку методов расчета устойчивости склона, в программных комплексах «SCAD Office» и «Plaxis» была

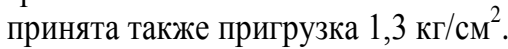

\section{Расчет устойчивости склонов}

программным комплексом «PSK-98M5»

В основе программы «PSK-98M5» лежит математическая модель в виде системы уравнений предельного равновесия, отражающих соотношение сдвигающих и удерживающих сил в грунтовом массиве с учетом сил взаимодействия по боковым граням расчетных отсеков и соответствующих напряженному состоянию массива непосредственно перед началом смещения оползня.

Данная программа осуществляет автоматический поиск поверхности смещения (реальной или потенциальной) оползня, определяя поверхность с минимальным коэффициентом устойчивости. Алгоритм поиска позволяет анализировать поверхность скольжения любой формы без ограничений на количество точек перегиба.

Программа производит автоматическое разбиение склона на блоки заданной длины, разбиение регулируется по высоте и по профилю в широких пределах. Коэффициент устойчивости рассчитывается итерационным методом путем решения системы уравнений равновесия горизонтальных и вертикальных сил для блоков плоской модели склона.

Предусмотрена возможность учитывать силы давления напорных подземных вод, силу давления фильтрационного потока, воздействие различных пригрузок и сейсмических (в т. ч. взрывных) ускорений.

Все расчеты показали достаточный запас устойчивости К в в пределах 2,71 (табл. 1) - 2,97 (табл. 2). Результаты расчетов устойчивости склона по линиям разреза 2-2a и 3-3а представлены, соответственно, в табл. 1, 2.

Таблица 1. Результаты расчетов устойчивости склона по линии разреза 2-2а при прогнозном уровне грунтовых вод (УГВ)

Table 1. Results of calculations of slope stability along the section line 2-2a at the forecast ground water level

\begin{tabular}{|c|c|c|c|c|c|}
\hline 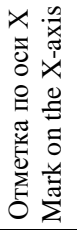 & 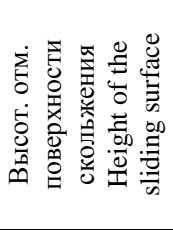 & 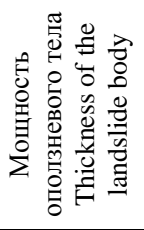 & 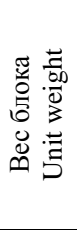 & 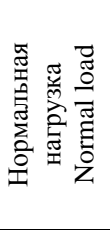 & 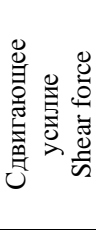 \\
\hline \multicolumn{3}{|c|}{$\mathrm{M} / \mathrm{m}$} & \multicolumn{3}{|c|}{$\mathrm{T}_{\mathrm{c}} / \mathrm{T}_{\mathrm{s}}$} \\
\hline 24,0 & 175,0 & 0,0 & 0,0 & 0,0 & 0,0 \\
\hline 28,0 & 172,3 & 2,42 & 9,5 & 8,0 & 2,3 \\
\hline 32,0 & 170,1 & 4,48 & 27,1 & 23,4 & 2,8 \\
\hline 36,0 & 168,3 & 5,89 & 40,6 & 37,3 & 10,9 \\
\hline 40,0 & 166,4 & 7,25 & 51,5 & 46,5 & 23,3 \\
\hline 44,0 & 165,0 & 8,16 & 60,4 & 59,1 & 33,4 \\
\hline 48,0 & 164,0 & 8,40 & 64,9 & 66,5 & 38,4 \\
\hline 52,0 & 163,0 & 8,62 & 66,7 & 64,2 & 44,8 \\
\hline 56,0 & 162,4 & 8,19 & 65,9 & 70,1 & 43,5 \\
\hline 60,0 & 161,8 & 7,79 & 58,5 & 57,3 & 42,4 \\
\hline 64,0 & 161,6 & 6,60 & 49,6 & 54,2 & 34,8 \\
\hline 68,0 & 161,8 & 4,00 & 34,6 & 38,0 & 26,2 \\
\hline 72,0 & 162,9 & 3,00 & 23,8 & 28,6 & 14,4 \\
\hline 76,0 & 165,4 & 0,00 & 11,8 & 14,0 & 0,0 \\
\hline
\end{tabular}



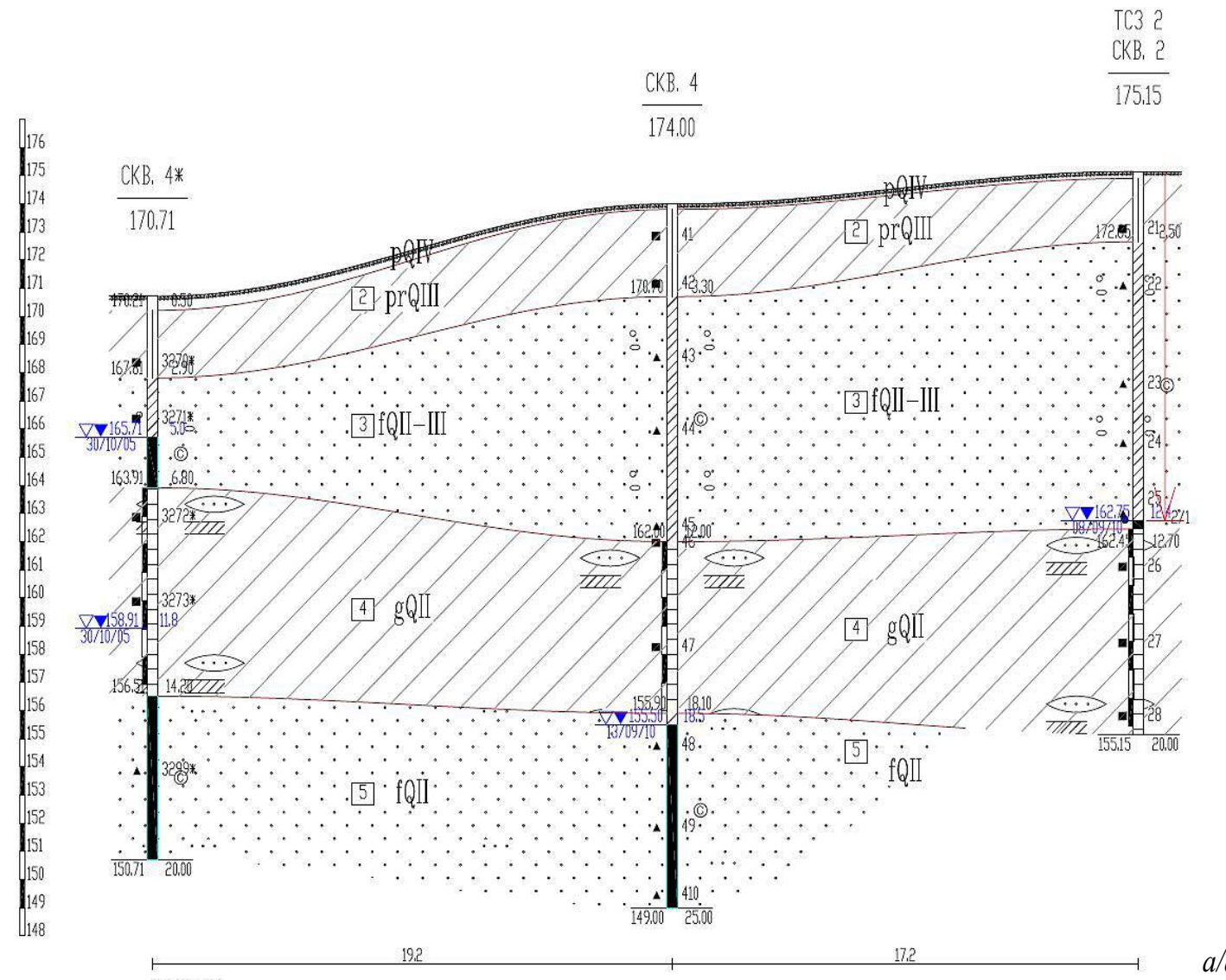

TC3 3

$\frac{\mathrm{CKB}, 3}{175.10}$

$a / a$

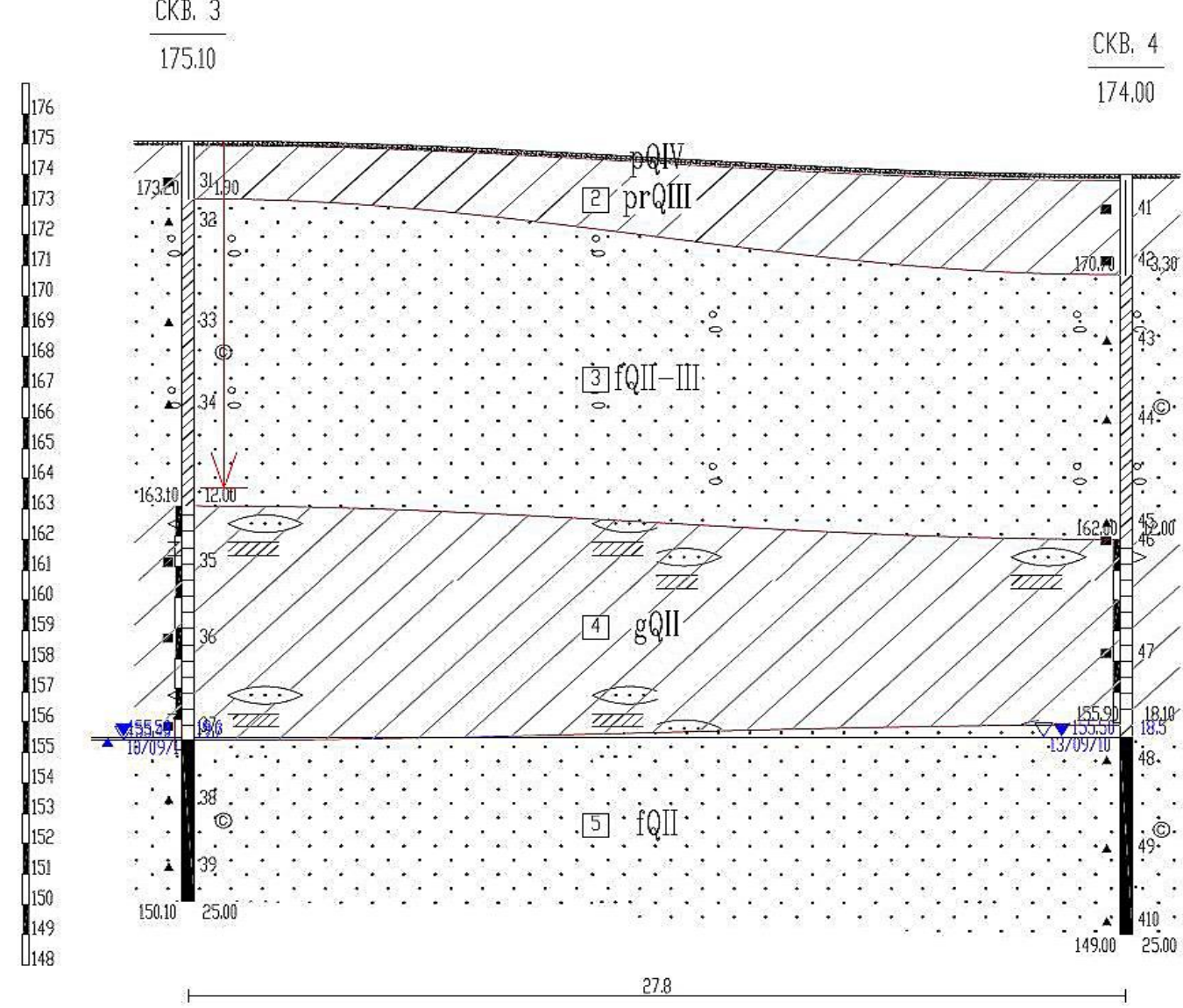

Pис. 1. Инженерно-геологические разрезы по линиям 2-2a (a) и 3-3а (б)

Fig. 1. Engineering and geological sections along lines 2-2a (a) and 3-3a (b) 
Таблица 2. Результаты расчетов устойчивости склона по линии разреза 3-3а при прогнозном уровне грунтовых вод (УГВ)

Table 2. Results of calculations of slope stability along the section line 3-3a at the forecast ground water level $(U G V)$

\begin{tabular}{|c|c|c|c|c|c|}
\hline 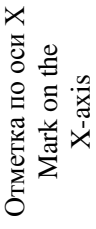 & 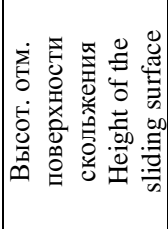 & 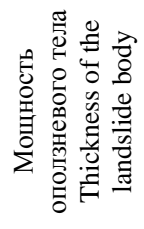 & 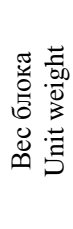 & 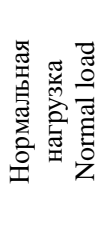 & 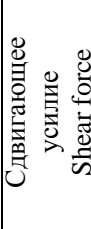 \\
\hline \multicolumn{3}{|c|}{$\mathrm{M} / \mathrm{m}$} & \multicolumn{3}{|c|}{$\mathrm{T}_{\mathrm{c}} / \mathrm{T}_{\mathrm{s}}$} \\
\hline 34,0 & 175,7 & 0,02 & 0,0 & 0,0 & 0,0 \\
\hline 36,0 & 173,9 & 1,73 & 5,4 & 4,1 & 0,3 \\
\hline 38,0 & 172,8 & 2,83 & 8,9 & 7,8 & 3,6 \\
\hline 40,0 & 172,0 & 3,57 & 12,1 & 11,8 & 6,3 \\
\hline 42,0 & 171,3 & 4,16 & 14,3 & 13,9 & 8,9 \\
\hline 44,0 & 170,8 & 4,38 & 15,6 & 15,5 & 10,9 \\
\hline 46,0 & 170,3 & 4,48 & 16,0 & 16,2 & 12,0 \\
\hline 48,0 & 170,0 & 4,46 & 15,9 & 16,4 & 12,2 \\
\hline 50,0 & 169,8 & 4,26 & 15,4 & 16,0 & 11,5 \\
\hline 52,0 & 169,7 & 3,94 & 14,5 & 15,1 & 10,0 \\
\hline 54,0 & 169,5 & 3,91 & 14,0 & 13,2 & 9,7 \\
\hline 56,0 & 169,4 & 3,85 & 14,2 & 14,7 & 8,4 \\
\hline 58,0 & 169,4 & 2,61 & 12,2 & 12,7 & 6,5 \\
\hline 60,0 & 170,5 & 0,14 & 5,4 & 7,9 & 0,0 \\
\hline
\end{tabular}

\section{Расчет устойчивости склонов} программным комплексом «SCAD Office»

Расчет устойчивости склона и поиск наиболее вероятной поверхности скольжения осуществляется при заданных интервалах его начала и конца. В данной программе это четыре числа: $\mathrm{r}_{1}, \mathrm{r}_{2}$, определяющие интервал изменения допускаемых значений абсцисс начала оползня, и аналогичные данные для конца оползня $-\mathrm{r}_{3}, \mathrm{r}_{4}$.

Необходимо, чтобы выполнялись следующие правила задания значений $\mathrm{r}: \mathrm{r}_{4}>\mathrm{r}_{1} ; \mathrm{r}_{2} \geq \mathrm{r}_{1} ; \mathrm{r}_{4} \geq \mathrm{r}_{3}$. Учитывая вышесказанное, принято, что $\mathrm{r}_{1}=5,5 \mathrm{~m} ; \mathrm{r}_{2}=10,2 \mathrm{~m}$; $\mathrm{r}_{3}=28,4$ м; $\mathrm{r}_{4}=40$ м для обеих расчетных линий. Уклон склона задается путем ввода абсолютных значений высот по скважинам.

Расчеты велись по трем из восьми методик, предложенных в программном комплексе «SCAD Office»: по методу Феллениуса, Бишопа и «Корпуса инженеров № 1».

Коэффициенты запаса устойчивости по линиям 2-2а и 3-3а, полученные по трем вышеуказанным методам, представлены в табл. 3.

Таблица 3. Коэффициенты запаса устойчивости

Table 3. Stability margin coefficients

\begin{tabular}{|c|c|c|c|}
\hline $\begin{array}{c}\text { Метод расчета } \\
\text { Calculation } \\
\text { method }\end{array}$ & $\begin{array}{c}\text { Метод } \\
\text { Феллениуса } \\
\text { расчета } \\
\text { Calculationius } \\
\text { Method }\end{array}$ & $\begin{array}{c}\text { Метод } \\
\text { Бишопа } \\
\text { Bishop } \\
\text { Method }\end{array}$ & $\begin{array}{c}\text { Метод «Корпу- } \\
\text { са инженеров } \\
\text { № 1» } \\
\text { Method of } \\
\text { «Corps of engi- } \\
\text { neers no. 1» }\end{array}$ \\
\hline $\begin{array}{c}\text { Линия 2-2a } \\
\text { Line 2-2a }\end{array}$ & 4,5 & 4,7 & 4,5 \\
\hline $\begin{array}{c}\text { Линия 3-3a } \\
\text { Line 3-3a }\end{array}$ & 12,2 & 12,3 & 12,1 \\
\hline
\end{tabular}

Анализируя полученные результаты, можно сделать вывод, что коэффициент запаса устойчивости по трем представленным методам практически не отличаются и в среднем для линии 2-2а равен 4,6, а для линии $3-3 a-12,2$, т. е. склон остается устойчивым.

Это еще раз доказывает, что все три метода всего лишь разновидности общего для всех метода круглоцилиндрической поверхности скольжения.

Что же касается такого различия коэффициентов устойчивости между расчетными линиями, то это, по всей видимости, связано с различными уклонами склона по эти двум направлениям (по линии 2-2а перепад высот 4,44 м, а по линии 3-3a-1,10 м).

Так как предполагаемые линии скольжения не имеют отличий между методами расчета, а отличаются только по расчетным сечениям, то целесообразно представить только линии скольжения, характеризующие расчетные сечения 2-2a, 3-3a (рис. 2).

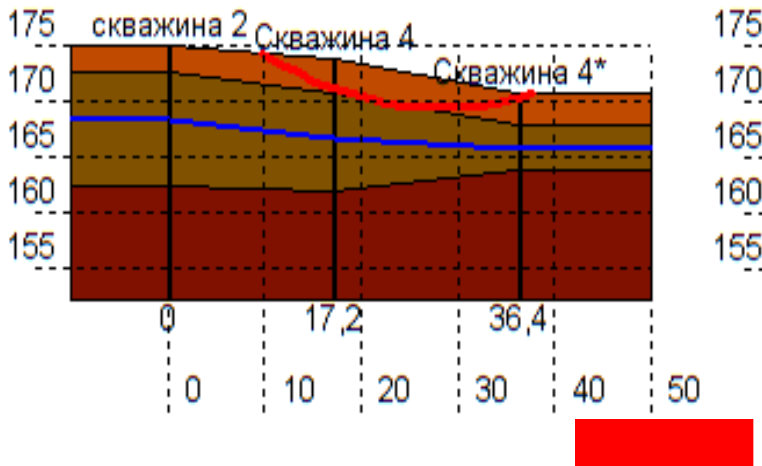

$a / a$
175 Скважина 3

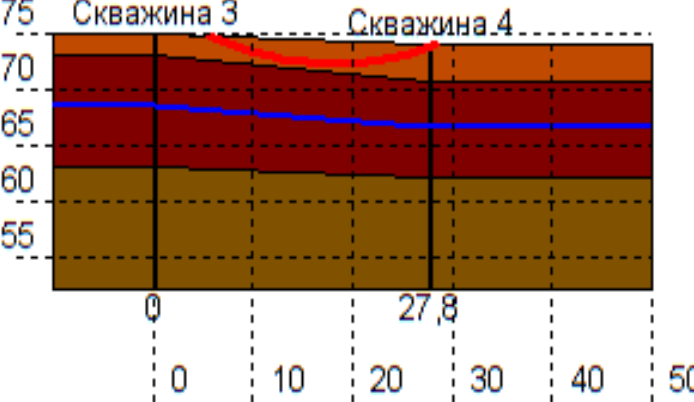

Линия скольжения

$\sigma / b$

Pис. 2. Предполагаемая линия скольжения по расчетному сечению 2-2a (a) и 3-3a (б)

Fig. 2. Estimated sliding line for the calculated cross section 2-2a (a) and 3-3a (b)

Расчет устойчивости склонов программным комплексом «Plaxis»

Программный комплекс «Plaxis» - это один из наиболее новых, точных продвинутых и популярных пакетов программ для выполнения разного рода ин- женерных (в том числе и инженерно-геологических) расчетов [17].

Plaxis представляет собой специализированную двухмерную и трехмерную компьютерную программу, основанную на МКЭ. 
Реальная ситуация может быть смоделирована с помощью модели плоской деформации или осесимметричной модели.

Программа имеет удобный графический интерфейс, который дает пользователю возможность быстро создавать геометрическую модель и сетку конечных элементов, основанную на представленном вертикальном поперечном разрезе [18, 19 и др.].

Механическое поведение каждого элемента выражается с помощью конечного числа степеней свободы или значений функций в узловых точках.

Таким образом, поведение математической модели определяется поведением дискретной модели, которая получена путем сборки всех элементов.

Основными типами конечных элементов являются: собственная размерность, узловые точки, геометрия элемента, степени свободы, узловые силы, определяющие соотношения, свойства сечения [20].

Геометрические параметры склона по двум расчетным сечениям для удобства, наглядности полученных результатов и более точного сравнения задавались такими же, как и в программе «PSK-98М5».

В результате расчета коэффициент устойчивости

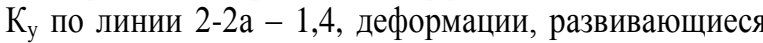
при этом в грунте, представлены на рис. 3. Важно отметить, что деформации развиваются совсем незначительные только внизу склона, а соответственно никакого негативного влияния на сооружение они оказывать не будут, что подтверждает также коэффициент устойчивости, равный, как упоминалось выше, 1,4.

По расчетному сечению 3-3а коэффициент устойчивости $\mathrm{K}_{\text {у }}$ равен 2,6, деформации в грунте (рис. 4) здесь выражены намного сильнее, чем в первом случае. Это, видимо, связано с более резким уклоном склона у его подножия.
Несмотря на более высокие деформации, склон остается устойчивым и негативного влияние на сооружение не оказывает.

Однако известно, что в ходе изысканий техническое задание было изменено и нагрузки увеличились до $30 \mathrm{~T} / \mathrm{m}^{2}$.

В таком случае было целесообразно провести расчет устойчивости склона при данной нагрузке по оптимальному расположению склона (у его подножия или вверху склона) наиболее эффективным методом методом конечных элементов.

Физико-механические характеристики свойств грунтов остаются теми же, что и в предыдущих расчетах. Расчет проводился по расчетному сечению 3-3a.

Рассмотрим, два случая расположения сооружения:

1) сооружение находится выше по склону. Коэффициент устойчивости склона по линии 3-3а равен 2,4. Деформации в грунте развиваются (рис. 5) значительные, но при этом они не приводят к оползанию склона, о чем говорит достаточно высокий коэффициент устойчивости.

2) сооружение находится у подножия склона. Коэффициент устойчивости склона при таком расположении сооружения уменьшился и составил 1,8 . Картина распределения деформаций в грунте представлена на рис. 6.

Из результатов расчетов следует, что более высокий коэффициент устойчивости получен при расположении нагрузки от проектируемого сооружения выше по склону, и, наоборот, при расположении ниже по склону той же нагрузки коэффициент устойчивости уменьшается.

Поэтому рекомендуется располагать здание выше по склону, чтобы обеспечить значительный запас устойчивости и избежать возможных негативных последствий при оползании склона, которые могут нанести вред здоровью человека.

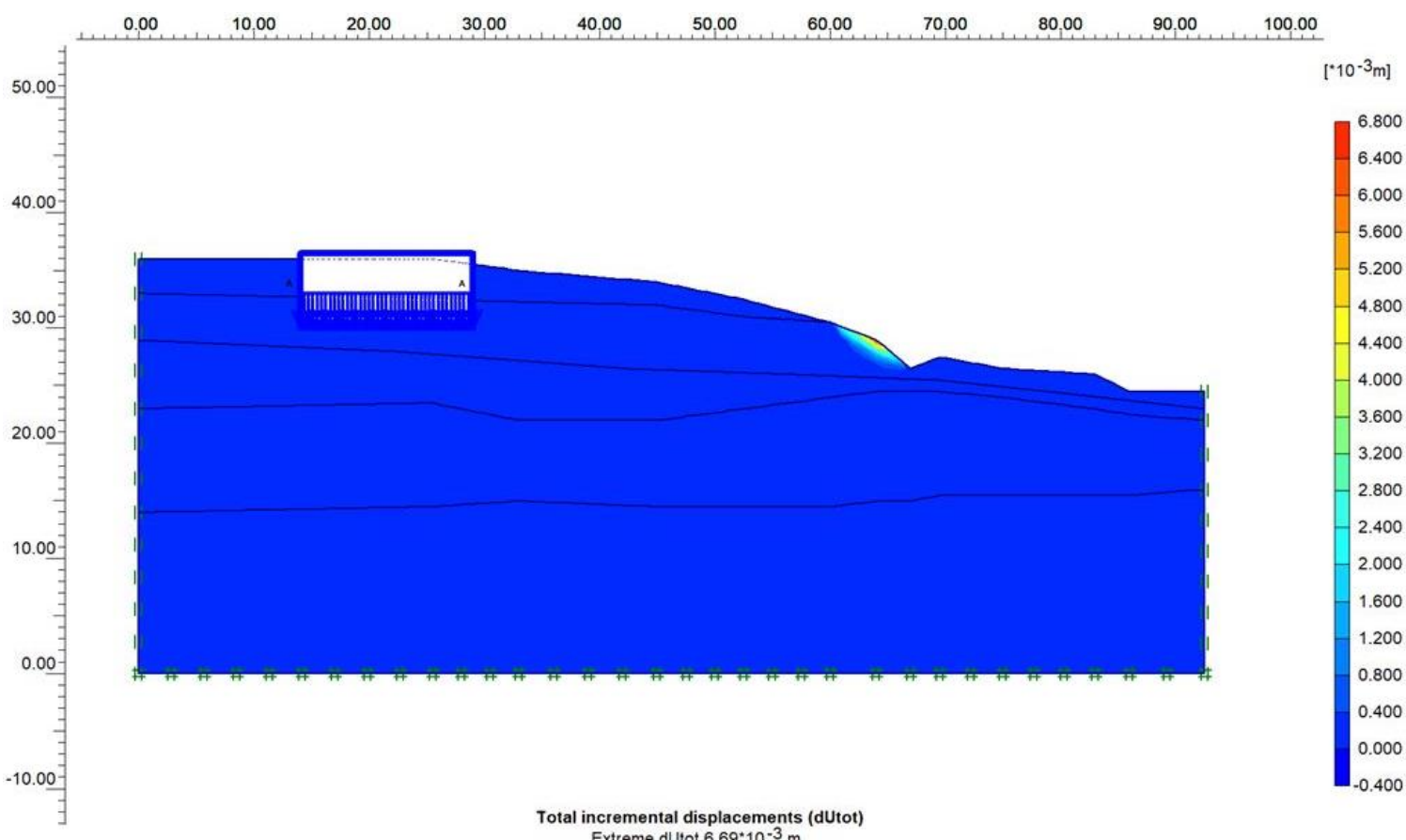

Pис. 3. Развитие деформаций в грунте по расчетному сечению $2-2 a$

Fig. 3. Development of deformations in the ground according to the calculated cross-section 2-2a 
Известия Томского политехнического университета. Инжиниринг георесурсов. 2021. Т. 332. № 6. 198-208

Ушаков А.С., Кулешов А.П. Прогноз устойчивости склонов участка берега Химкинского водохранилища

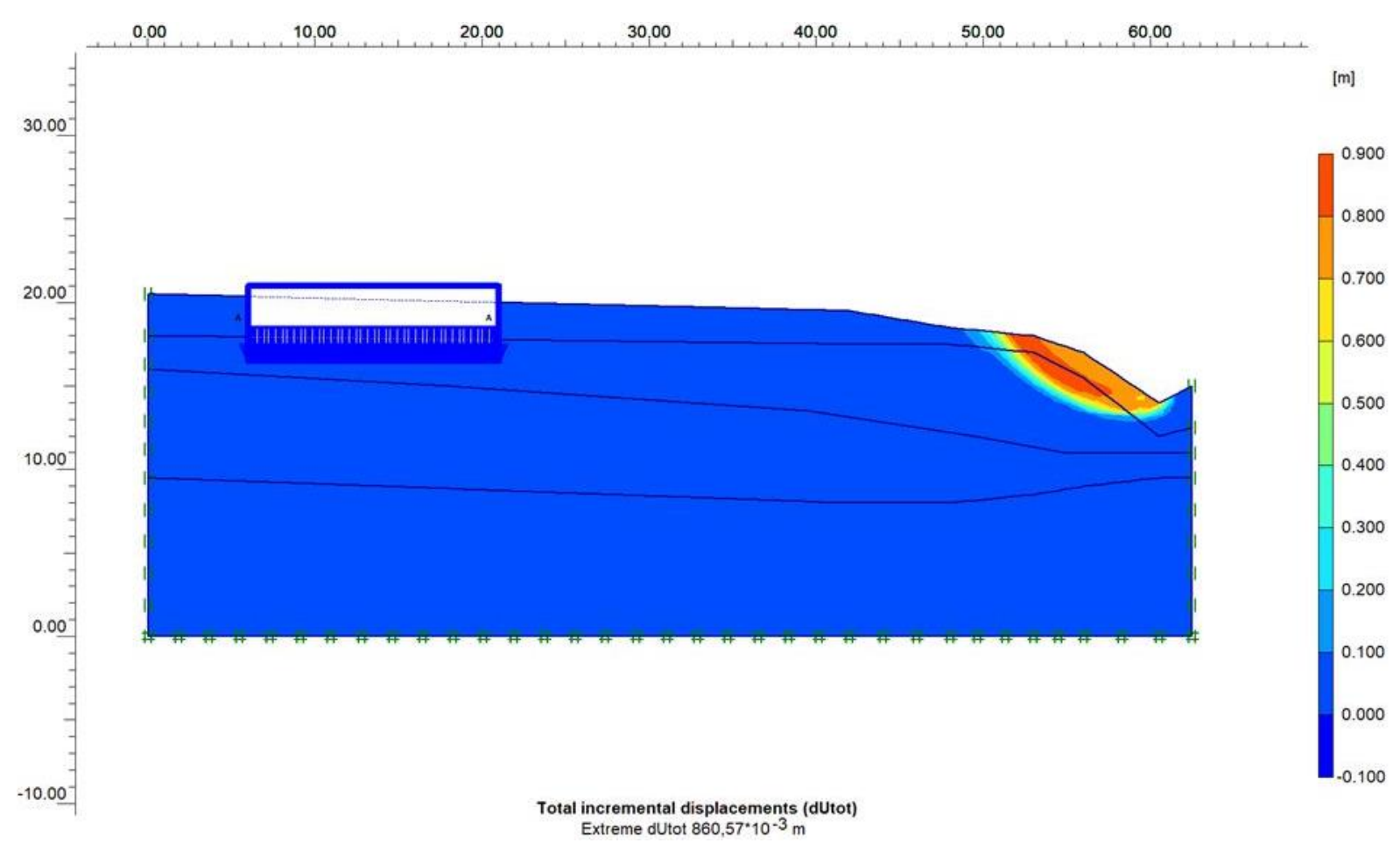

Pис. 4. Развитие деформаций в грунте по расчетному сечению 3-3а

Fig. 4. Development of deformations in the ground according to the calculated cross-section 3-3a

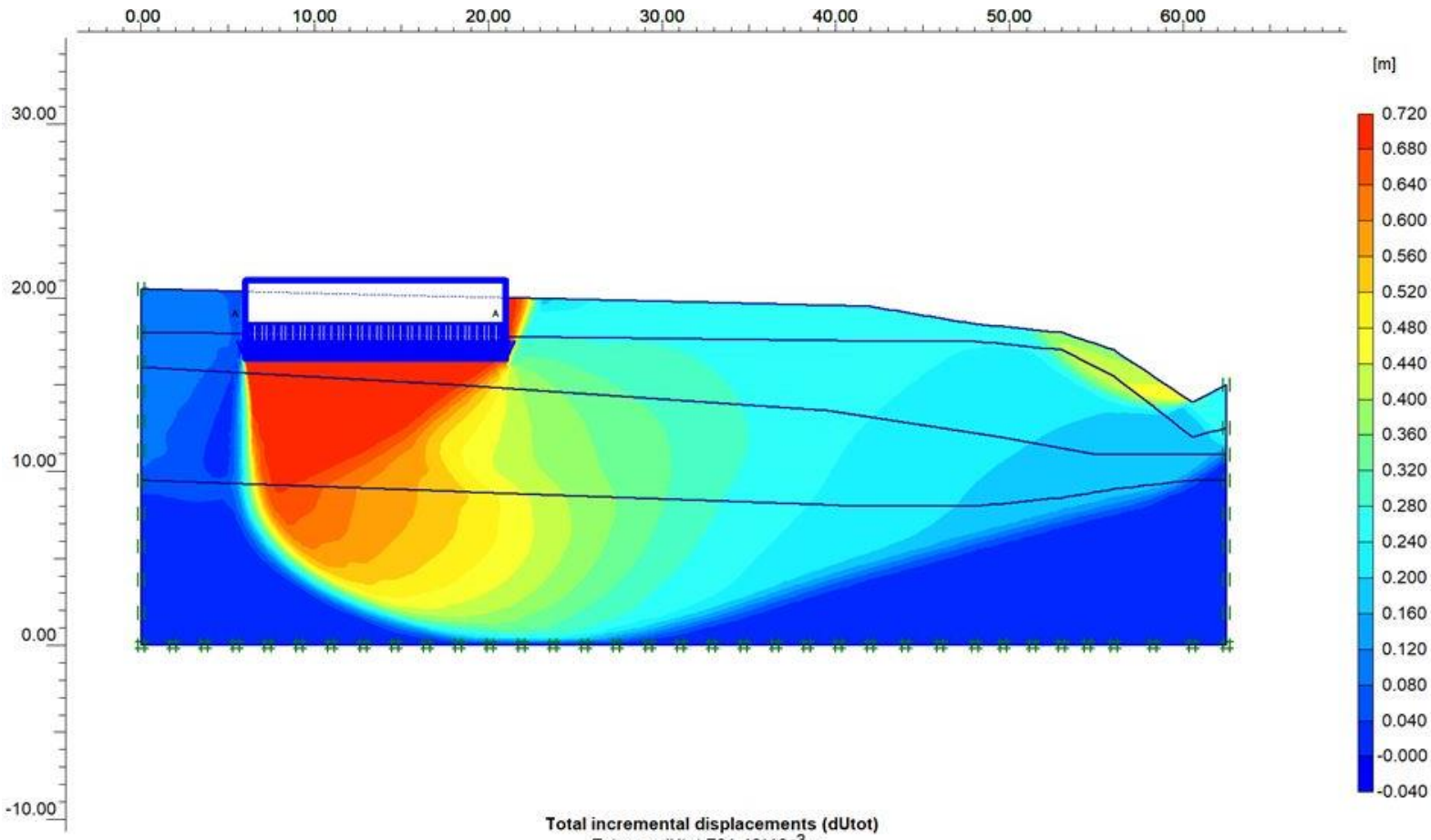

ental displacements (dUtot)

Рис. 5. Развитие деформаций в грунте по расчетному сечению $3-3$ а при нагрузке $30 \mathrm{~m} / \mathrm{m}^{2}$ (сооружение - выше по склону)

Fig. 5. Development of deformations in the ground along the calculated cross-section 3-3a at a load of $30 \mathrm{t} / \mathrm{m}^{2}$ (construction is higher up the slope) 


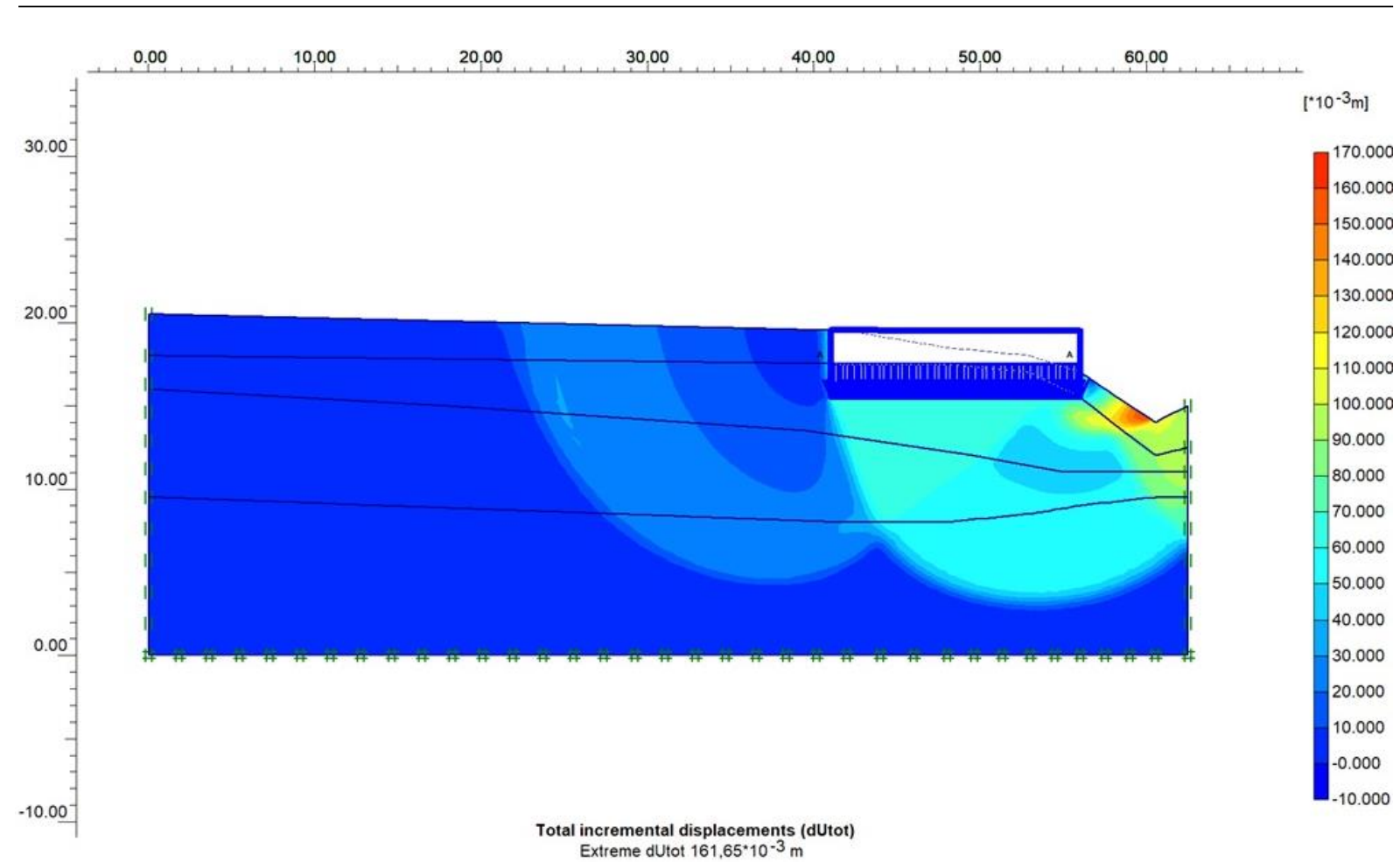

Pис. 6. Развитие деформаций в грунте по расчетному сечению 3-3а при нагрузке $30 \mathrm{~m} / \mathrm{m}^{2}$ (сооружение - у подножия склона)

Fig. 6. Development of deformations in the ground according to the calculated cross-section 3-3a at a load of $30 \mathrm{t} / \mathrm{m}^{2}$ (construction is at the foot of the slope)

\section{Результаты исследования и их обсуждение}

Для удобства анализа все значения, полученные в результате расчетов по трем программам, коэффициента устойчивости сведены в табл. 4.

Таблица 4. Сравнительная таблица коэффициентов устойчивости склона

Table 4. Comparative table of slope stability coefficients

\begin{tabular}{|c|c|c|c|}
\hline \multirow{2}{*}{$\begin{array}{r}\text { Методы } \\
\text { расчета } \\
\text { устойчивости } \\
\text { Methods for } \\
\text { calculating } \\
\text { stability }\end{array}$} & \multirow{2}{*}{ 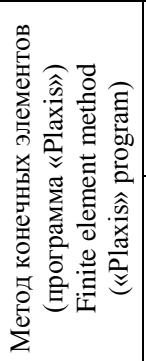 } & \multicolumn{2}{|c|}{$\begin{array}{l}\text { Метод круглоцилиндриче- } \\
\text { ской поверхности } \\
\text { скольжения } \\
\text { Round-cylindrical sliding } \\
\text { surface method }\end{array}$} \\
\hline & & $\begin{array}{c}\text { Программа } \\
\text { «SCAD Office» } \\
\text { «SCAD Office» } \\
\text { program }\end{array}$ & $\begin{array}{c}\text { Программа } \\
\text { «PSK-98M5» } \\
\text { «PSK-98M5» } \\
\text { program }\end{array}$ \\
\hline $\begin{array}{l}\text { Сечение 2-2a } \\
\text { Line 2-2a }\end{array}$ & 1,4 & 4,6 & 2,97 \\
\hline $\begin{array}{c}\text { Сечение 3-3a } \\
\text { Line 3-3a }\end{array}$ & 2,6 & 12,2 & 2,71 \\
\hline
\end{tabular}

Коэффициент запаса устойчивости получился больше единицы, а это означает, что склон устойчив и никакого негативного влияния при таких нагрузках

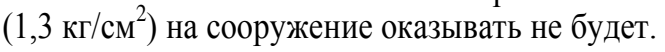

\section{СПИСОК ЛИТЕРАТУРЫ}

1. Буфеев Ф.К., Фоменко И.К. Влияние методов расчёта и моделей распределения свойств грунтов на результаты количественной оценки устойчивости склонов // Известия высших
Как видно из результатов, программный комплекс «SCAD Office» дает завышенные значения. Это связано, по всей видимости, с тем, что в данной программе геометрические параметры склона фактически никак не вводятся. Уклон рельефа создается только за счет ввода абсолютных отметок по скважинам. Поэтому коэффициенты устойчивости склона, полученные этой программой, являются не совсем достоверными.

Из оставшихся двух методов и двух программ наиболее приближенными к действительности являются результаты полученные в программе «Plaxis», так как она разбивает введенную модель на огромное количество простых геометрических фигур (треугольников) и значения коэффициента считаются в каждой узловой точке. Это обстоятельство существенно увеличивает точность расчета и намного приближает математическую модель к природным условиям.

Так как коэффициент устойчивости, полученный при расположении сооружения у подножия склона, меньше, чем аналогичный выше по склону, то рекомендуется располагать здание выше по склону, чтобы обеспечить значительный запас устойчивости и избежать возможных негативных последствий при оползании склона, которые могут нанести вред здоровью человека.

учебных заведений. Геология и разведка. - 2016. - № 2. С. $33-38$.

2. Пургина Д.В., Строкова Л.А., Кузеванов К.И. Моделирование гидрогеологических условий для обоснования противооползневых мероприятий на участке набережной реки Камы в горо- 
де Пермь // Известия Томского политехнического университета. Инжиниринг георесурсов. - 2016. - Т. 327. - № 1. - С. 116-127.

3. Сравнительный анализ методов расчета устойчивости склона в объемной постановке задачи / О.Н. Сироткина, В.В. Тарабукин, И.К. Фоменко, Д.Д. Шубина // Международный научноисследовательский журнал. - 2020. - Т. 99. - № 9. - С. 55-62.

4. Кулешов А.П., Пендин В.В. Влияние методики определения свойств грунтов в численных расчетах деформаций // Известия Томского политехнического университета. Инжиниринг георесурсов. - 2017. - Т. 328. - № 12. - С. 63-74.

5. Оценка оползневого риска (на примере северо-западной части провинции Лаокай, Вьетнам) / Ч.К. Нгуен, И.К. Фоменко, О.В. Зеркаль, В.В. Пендин // Инженерная геология. - 2018. T. 13. - № 3. - C. 40-53.

6. Пендин В.В. Комплексный количественный анализ информации в инженерной геологии. - М.: КДУ, 2009. - 350 с.

7. Строкова Л.А., Ермолаева А.В. Районирование территории по степени опасности оседания земной поверхности при проектировании магистрального газопровода в южной Якутии // Известия Томского политехнического университета. Инжиниринг георесурсов. - 2016. - Т. 327. - № 10. - С. 59-68.

8. СП 22.13330.2016. Основания зданий и сооружений. - М.: Стандартинформ, 2016. - 69 с.

9. Строкова Л.А., Епифанова Е.А., Коржнева Т.Г. Численный анализ поведения основания опоры моста на старой железнодорожной линии // Известия Томского политехнического университета. Инжиниринг георесурсов. - 2017. - Т. 328. - № 5 . C. $125-139$.

10. Улицкий В.М., Шашкин А.Г. Геотехническое сопровождение реконструкции городов. - М.: Изд-во АСВ, 1999. - 327 с.

11. Фоменко И.К., Зеркаль О.В. Оценка устойчивости склонов при инженерных изысканиях: нормативные требования и проблемы их выполнения // Инженерные изыскания. - 2016. № 10-11. - C. 64-70.
12. Brakorenko N.N. Impact of oil on groundwater chemical composition // IOP Conference Series: Earth and Environmental Science. -2015 . - № 27. $-6 \mathrm{p}$.

13. Slope stability and stabilization methods / L.W. Abramson, T.S. Lee, S. Sharma, G.M. Boyce. - New York, USA: John Wiley \& sons, 2002. $-736 \mathrm{p}$

14. Plaxis. Material Models Manual. - 216 p. URL: https://www.plaxis.ru (дата обращения 11.09.2020)

15. Phi H.T., Strokova L.A. Prediction maps of land subsidence caused by groundwater exploitation in Hanoi, Vietnam // Resource Efficient Technologies. - 2015. - V. 1. - Iss. 2. - P. 80-89.

16. Terrestrial laser scanning technology for deformation monitoring and surface modeling of arch structures / H. Yang, M. Omidalizarandi, X. Xu, I.I. Neumann // Composite Structures. - 2016. - V. 149. - P. 93-105.

17. Gitirana G. (Jr.), Santos M.A., Fredlund M. Three-dimensional analysis of the Lodalen landslide // Proceedings of the GeoCongress. - New Orleans, 2008. - $5 \mathrm{p}$.

18. Yardim Y., Mustafaraj E. Effects of soil settlement and deformed geometry on a historical structure // Natural hazards and Earth System Sciences. - 2015. - V. 15. - P. 1051-1059.

19. Terrestrial laser scanner for monitoring the deformations and the damages of buildings / G. Vacca, F. Mistretta, F. Stochino, A. Dessi // International Archives of the Photogrammetry, Remote Sensing \& Spatial Information Sciences. - 2016. - V. 41. Iss. B5. - P. 453-460.

20. Deformations of soil in deep excavations: Comparing calculation results with in-situ measurements / V.M. Ulitsky, A.G. Shashkin, K.G. Shashkin, M.B. Lisyuk, V.A. Vasenin // Proc. of the 17th International Conference on Soil Mechanics and Geotechnical Engineering: the Academia and Practice of Geotechnical Engineering. - St. Petersburg, 2009. - V. 3. P. $2107-2110$

Поступила 06.10.2020 г.

\section{Информация об авторах}

Уиаков A.C., аспирант кафедры инженерной геологии Российского государственного геологоразведочного университета им. Серго Орджоникидзе.

Кулешов А.П., кандидат геолого-минералогических наук, доцент кафедры инженерной геологии Российского государственного геологоразведочного университета им. Серго Орджоникидзе. 
UDC 624.131

\title{
FORECAST OF SLOPE STABILITY OF THE BANK SECTION OF THE KHIMKI RESERVOIR
}

\author{
Alexander C. Ushakov ${ }^{1}$ \\ ushakovi@inbox.ru
}

\author{
Alexander P. Kuleshov ${ }^{1}$, \\ 87kuleshov@mail.ru \\ 1 Sergo Ordzhonikidze Russian State Geological Prospecting University, \\ 23, Miklukho-Maklay street, Moscow, 117997, Russia.
} The relevance of the work is caused by the need to analyze the existing methods for calculating the slope stability coefficient. The paper
analyzes three calculation methods and provides an analysis of the rational use of each method. Recommendations on the choice of cal-
culation methods are developed based on the analysis of existing calculation methods and their comparison in relation to practical calculations.

The main aim: predictive calculation of the slope stability of the bank section of the Khimki reservoir, comparative analysis of the values of the stability coefficients obtained by various methods using modern mathematical tools implemented in software complexes: "PSK-98M5», "SCAD Office» and "Plaxis», evaluation of the possibility of using one of the applied numerical methods of calculation.

Methods: analysis of domestic and foreign experience in calculating slope stability, collection and evaluation of available engineering and geological information, selection of boundary conditions, application of analytical and numerical solutions, comparison of calculation results obtained by various methods, assessment of the vulnerability of objects and forecast of deformations in the base of buildings under the influence of landslide development.

Results. Mathematical calculations were performed by various software systems using several models and methods in accordance with the recommendations of the current regulatory documentation. From the results of calculations, it follows that a higher stability coefficient is obtained when the load from the designed structure is located higher up the slope, and vice versa, when the same load is located lower down the slope, the stability coefficient decreases. The «SCAD Office» software package gives inflated results. This is probably due to the fact that in this program, the geometric parameters of the slope are not actually entered in any way. The results obtained in the Plaxis program are the closest to reality, since it splits the entered model into a huge number of simple geometric shapes (triangles) and the coefficient values are calculated at each node point. This circumstance significantly increases the accuracy of the calculation and brings the mathematical model much closer to natural conditions.

\section{Key words:}

Stability forecast, margin coefficient, boundary conditions, deformations and stresses, sliding line, calculated cross-section, physical and mechanical characteristics, finite element method, software package, slope, comparative analysis.

\section{REFERENCES}

1. Bufeev F.K., Fomenko I.K. Influence of calculation methods and models of soil properties distribution on the results of quantitative assessment of slope stability. News of higher educational institutions. Geology and exploration, 2016, no. 2, pp. 33-38. In Rus.

2. Purgina D.V., Strokova L.A., Kuzevanov K.I. Modeling hydrogeological conditions for antilandslide measures justification on the plot of the Kama river embankment in Perm. Bulletin of the Tomsk Polytechnic University. Geo Assets Engineering, 2016, vol. 327, no. 1, pp. 116-127. In Rus.

3. Sirotkina O.N., Tarabukin V.V., Fomenko I.K., Shubina D.D. comparative analysis of methods for calculating slope stability in a three-dimensional problem statement. International scientific research journal, 2020, vol. 99, no. 9, pp. 55-62. In Rus.

4. Kuleshov A.P., Pendin V.V. Influence of methods for determining soil properties in numerical calculations of deformations. Proceedings of the Tomsk Polytechnic University. Geo Assets Engineering, 2017, vol. 328, no. 12, pp. 63-74.

5. Nguyen Ch.K., Fomenko I.K., Zerkal O.V., Pendin V.V. Landslide risk assessment (on the example of the North-Western part of the province of Lao Cai, Vietnam). Engineering Geology, PNIIS publishing house, 2018, vol. 13, no. 3, pp. 40-53. In Rus.

6. Pendin V.V. Kompleksny kolichestvenny analiz informatsii $v$ inzhenernoy geologii [Complex quantitative analysis of information in engineering Geology]. Moscow, KDU Publ., 2009. $350 \mathrm{p}$.

7. Strokova L.A., Ermolaeva A.V. Zoning according to the hazard level of earth surface subsidence when designing the main gas pipeline in south Yakutia. Bulletin of the Tomsk Polytechnic University. Geo Assets Engineering, 2016, vol. 327, no. 10, pp. 59-68.
8. SP 22.13330.2016 Osnovaniya zdaniy $i$ sooruzheniy [Code of rules 22.13330.2016. Soil bases of buildings and structures]. Moscow, Standartinform Publ., 2016. 69 p.

9. Strokova L.A., Epifanova E.A., Korzhneva T.G. Numerical analysis of bridge foundation behaviour on the old railway line. Bulletin of the Tomsk Polytechnic University. Geo Assets Engineering, 2017, vol. 328, no. 5, pp. 125-139. In Rus.

10. Ulitsky B.M., Shashkin A.G. Geotekhnicheskoe soprovozhdenie rekonstruktsii gorodov [Geotechnical support urban renewal]. Moscow, DIA Publ., 1999. 327 p.

11. Fomenko I.K., Zerkal O.V. Assessment of slope stability in engineering surveys: regulatory requirements and problems of their implementation. Engineering survey, 2016, no. 10-11, pp. 64-70. In Rus.

12. Brakorenko N.N. Impact of oil on groundwater chemical composition. IOP Conference Series: Earth and Environmental Science, 2015, no. 27, 6 p.

13. Abramson L.W., Lee T.S., Sharma S., Boyce G.M. Slope stability and stabilization methods. New York, USA, John Wiley \& Sons, 2002. $736 \mathrm{p}$.

14. Plaxis. Material Models Manual. 216 p. Available at: https://www.plaxis.ru (accessed 11 September 2020).

15. Phi H.T., Strokova L.A. Prediction maps of land subsidence caused by groundwater exploitation in Hanoi, Vietnam. Resource Efficient Technologies, 2015, vol. 1, Iss. 2, pp. 80-89.

16. Yang H., Omidalizarandi M., Xu X., Neumann I.I. Terrestrial laser scanning technology for deformation monitoring and surface modeling of arch structures. Composite Structures, 2016, vol. 149, pp. $93-105$.

17. Gitirana G. (Jr.), Santos M.A., Fredlund M. Three-dimensional analysis of the Lodalen landslide. Proc. of the GeoCongress'2008. New Orleans, 9-12 March 2008. 5 p. 
18. Yardim Y., Mustafaraj E. Effects of soil settlement and deformed geometry on a historical structure. Natural hazard and Earth system Sciences, 2015, vol. 15, pp. 1051-1059.

19. Vacca G., Mistretta F., Stochino, F., Dessi A. Terrestrial laser scanner for monitoring the deformations and the damages of buildings. International Archives of the Photogrammetry, Remote Sensing \& Spatial Information Sciences, 2016, vol. 41, Iss. B5, pp. $453-460$.
20. Ulitsky V.M., Shashkin A.G., Shashkin K.G., Lisyuk M.B. Vasenin V.A. Deformations of soil in deep excavations: Comparing calculation results with in-situ measurements. Proc. of the $17^{\text {th }}$ International Conference on Soil Mechanics and Geotechnical Engineering: The Academia and Practice of Geotechnical Engineering. St. Petersburg, 2009. Vol. 3, pp. 2107-2110.

Received: 6 October 2020.

\section{Information about the authors}

Alexander C. Ushakov, postgraduate, Sergo Ordzhonikidze Russian State Geological Prospecting University. Alexander P. Kuleshov, Cand. Sc., associate professor, Sergo Ordzhonikidze Russian State Geological Prospecting University. 